\title{
Staphylococcus aureus nasal carriage and related risk factors in diabetic foot patients
}

İlhan Kurultak ${ }^{1}$ Mustafa Altay ${ }^{2}$ Salih Cesur $^{3}$ Eda Yıldız ${ }^{4}$ Murat Duranay ${ }^{5}$

Trakya University Medical Faculty, Department of Nephrology, Edirne, Turkey 1

Keçiören Education and Research Hospital, Department of Endocrinology and Metabolism, Ankara, Turkey ${ }^{2}$

Ankara Education and Research Hospital, Department of Infectious Disease and Clinical Microbiology, Ankara, Turkey ${ }^{3}$

Ankara Education and Research Hospital, Department of Microbiology, Ankara, Turkey 4

Ankara Education and Research Hospital, Department of Nephrology, Ankara, Turkey ${ }^{5}$

\section{INTRODUCTION}

Infections are the major cause of increased mortality and morbidity rate in diabetic foot patients. There are little data in literature about the effects of $S$. aureus nasal carriage on DF infection, the risk factors that influence nasal carriage and its incidence in diabetics. We aimed to detect of the incidence, risk factors and relationship between wound culture and $\mathrm{S}$. aureus nasal carriage in diabetic patients who have DF with this study.

\section{MATERIAL and METHODS}

The study was designed as a prospective, cross-sectional, controlled study. Group 1(n=40): nondiabetic patients, Group 2(n=40): diabetics patients without DF, Group 3: $(n=40)$ : diabetics patients with DF. The incidence of S. aureus nasal carriage and effects of determined factors to nasal carriage were investigated in these three groups. The relationship between nasal carriage and wound culture was analyzed in the last group.

\section{RESULTS}

We found the incidence of $S$. aureus nasal carriage $17.5 \%, 20 \%$ and $10 \%$ in the groups 1 to 3 respectively $(P=0.47)$. Determined parameters (age, sex, usage of insulin/oral anti-diabetic drugs, time of diabetes, level of $\mathrm{HbA} 1 \mathrm{c}$, levels of fasting and after meal glucose) did not affect the $S$. aureus nasal carriage. We did not detect the relationship between wound cultures and nasal swap cultures in group

3. We observed no effect of the history of antibiotic usage in the last six months and existence of hospitalization or operation on S. aureus nasal carriage

\section{DISCUSSION}

We detected that having diabetes and/or DF did not alter the risk of S. aureus nasal carriage and also carriage did not affect the results of wound culture. Better designed studies are needed for the detection of possible relationship between the factors belongs to the patients who have higher risk for S.aureus infections and nasal carriage 